\title{
Evaluation of body composition in COPD patients using multifrequency bioelectrical impedance analysis
}

This article was published in the following Dove Press journal:

International Journal of COPD

30 September 2016

Number of times this article has been viewed

\section{Francesca de Blasio' \\ Francesco de Blasio ${ }^{2,3}$ \\ Giulia Miracco Berlingieri ${ }^{2}$ \\ Andrea Bianco ${ }^{3,4}$ \\ Marta La Greca' \\ Frits M E Franssen ${ }^{5}$ \\ Luca Scalfi'}

'Department of Public Health, Medical School, "Federico II" University of Naples, ${ }^{2}$ Respiratory Medicine and Pulmonary Rehabilitation Section, Clinic Center, Private Hospital, Naples, ${ }^{3}$ Department of Medicine and Health Sciences "V Tiberio", University of Molise, Campobasso, ${ }^{4}$ Department of Cardio-Thoracic and Respiratory Sciences, Second University of Naples, Naples, Italy; ${ }^{5}$ Department of Research and Education, CIRO, Horn, the Netherlands
Correspondence: Francesca de Blasio Department of Public Health,

"Federico II" University of Naples Medical School, Via Pansini 5, 8013। Naples, Italy Email francesca.deblasio1989@gmail.com
Background: Multifrequency bioelectrical impedance analysis (MF-BIA) is a technique that measures body impedance $(\mathrm{Z})$ at different frequencies $(5,10,50,100$, and $250 \mathrm{kHz})$. Body composition may be estimated using empirical equations, which include BIA variables or, alternatively, raw BIA data may provide direct information on water distribution and muscle quality. Objectives: To compare raw MF-BIA data between COPD patients and controls and to study their relationship with respiratory and functional parameters in COPD patients.

Methods: MF-BIA was performed (Human Im-Touch analyzer) in 212 COPD patients and 115 age- and BMI-matched controls. Fat-free mass (FFM) and fat mass were estimated from BIA data, and low- to high-frequency $(5 \mathrm{kHz} / 250 \mathrm{kHz})$ impedance ratio was calculated. Physical fitness, lung function and respiratory muscle strength were also assessed in COPD patients.

Results: After adjusting for age, weight, and body mass index, FFM and the 5/250 impedance ratio were lower in COPD patients $(P<0.001)$ and were negatively affected by disease severity. In both male and female patients, the $5 / 250$ impedance ratio was significantly correlated mainly with age ( $r=-0.316$ and $r=-0.346$, respectively). Patients with a $5 / 250$ impedance ratio below median value had lower handgrip strength $(P<0.001)$, 6-minute walk distance $(P<0.005)$, respiratory muscle strength $(P<0.005)$, forced expiratory volume in 1 second $(P<0.05)$ and vital capacity $(P<0.005)$. Finally, the $5 / 250$ impedance ratio was reduced $(P<0.05)$ in patients with Global Initiative for Chronic Obstructive Lung Disease (GOLD) III and IV (compared to those with GOLD I and II) or a BODE index between 6 and 10 points (compared to those with BODE index between 1 and 5 points).

Conclusion: MF-BIA may be a useful tool for assessing body composition and nutritional status in COPD patients. In particular, the impedance ratio could give valuable information on cellular integrity and muscle quality.

Keywords: muscle quality, impedance ratio, muscle strength

\section{Introduction}

Nutrition and the evaluation of body composition play an increasingly central role in the diagnosis, assessment and management of COPD. Besides smoking cessation, pharmacological therapies and management of comorbidities, nutritional assessment has been recently confirmed to be one of the most important topics in COPD. ${ }^{1}$

COPD is frequently associated with one or more comorbidities (ie, hypertension, atherosclerosis, chronic heart failure, lung cancer, osteoporosis and depression) which contribute to the overall severity in individual patients. ${ }^{2-4}$ In addition to systemic effects, weight loss and muscle weakness are common and associated with alterations in body composition..$^{5-7}$ 
Low body mass index (BMI $<21 \mathrm{~kg} / \mathrm{m}^{2}$ ) is associated with increased mortality and reduced health status, quality of life and exercise capacity, independently of airflow limitation. ${ }^{8-11}$ In addition to BMI, which is insufficient to discriminate between the different body compartments, low fat-free mass (FFM) has been described in $\mathrm{COPD}^{12-14}$ and may be an even better predictor of clinical outcomes in these patients. ${ }^{10,11}$ Furthermore, recent interest has been focused on the impact of adipose tissue on chronic diseases including COPD through biologically active substances, adipokines, which regulate energy metabolism. ${ }^{15,16}$

Several techniques are available to assess body composition in COPD, including anthropometry, bioelectrical impedance analysis (BIA), dual-energy X-ray absorptiometry (DXA) and more advanced imaging technologies like computed tomography, high-resolution computed tomography and magnetic resonance imaging. ${ }^{17}$ The choice of method depends not only on the type of study and the number of compartments to be studied, but also on its applicability in clinical practice. ${ }^{18}$

BIA is the bedside method that has been most widely investigated in clinical research, due to its affordability, portability and ease of use. ${ }^{19}$ Actually, BIA does not directly measure body composition; estimates of body composition are derived from raw BIA data, such as impedance $(Z)$, resistance, reactance and phase angle, using predictive equations..$^{20}$ Alternatively, information about water distribution (between intracellular and extracellular compartments) and cell integrity may be obtained from raw BIA data, such as low- to high-frequency impedance ratio and phase angle. ${ }^{21-24}$

BIA can be applied for estimating body composition using data generated by single-frequency BIA (SF-BIA), multifrequency BIA (MF-BIA) or bioimpedance spectroscopy devices. ${ }^{20,25}$ In particular, MF-BIA devices measure $Z$ at several frequencies, usually in the range between 1 and $300 \mathrm{kHz} .^{20}$ At low frequency, the current does not pass through the cell membrane and is conducted only through extracellular water (ECW), whereas at high frequency, current penetrates cell membranes and is thus used to estimate total body water (TBW) ${ }^{26}$ As a consequence, low- to high-frequency impedance ratio (ie, $\mathrm{Z}$ at $5 \mathrm{kHz} / \mathrm{Z}$ at $250 \mathrm{kHz}$ ) is a derived MF-BIA variable which provides information on water distribution between intra- and extracellular compartments and therefore on body cell mass and muscle quality. ${ }^{21,24,27}$

In patients with COPD, BIA has usually been used to estimate FFM and body composition through predictive equations. Very few studies had focused on raw BIA data, ${ }^{28-30}$ and no comparison with healthy subjects has been carried out yet. In particular, no data on low- to high-frequency impedance ratio are available.

The general aim of this study was to evaluate whether MF-BIA is a useful tool for the assessment of nutritional status in COPD patients. More specifically, this study compared MF-BIA between COPD patients and matched controls and investigated the association of MF-BIA with sex, age, weight, BMI and FFM in COPD patients. Also, the relationships of MF-BIA with established markers of physical fitness, lung function and respiratory muscle strength in COPD patients were studied.

\section{Patients and methods Subjects}

Two hundred and sixty patients with COPD, consecutively admitted to the Pulmonary Rehabilitation Section of Clinic Center SPA (Naples, Italy) from March 2013 to November 2015, were assessed for eligibility. Inclusion criteria were age $>50$ years, BMI between 20 and $35 \mathrm{~kg} / \mathrm{m}^{2}$ and a baseline post-bronchodilator forced expiratory volume in 1 second $\left(\mathrm{FEV}_{1}\right)$ /forced vital capacity $(\mathrm{FVC})$ ratio $<70$. Exclusion criteria were related to diagnosis of known respiratory disorders other than COPD, known history of significant inflammatory disease other than COPD and a COPD exacerbation within 4 weeks of enrollment. Furthermore, a group of age- and BMImatched controls from a larger database was included. The Ethics Committee of the "Federico II" University of Naples approved the research protocol and all the patients gave verbal informed consent to participate in the study.

\section{Study protocol}

Starting at 9.30 AM, COPD patients and control subjects underwent body composition assessment. The same nutritionist always collected all the data. For COPD patients, respiratory and other clinical parameter measurements as well as physical fitness tests followed under the supervision of a chest physician.

\section{Body composition}

Body weight and body height were measured to the nearest $0.1 \mathrm{~kg}$ and $0.5 \mathrm{~cm}$, respectively, using a mechanical column scale (SECA 711+220; Seca GmbH \& Co. KG, Hamburg, Germany), and BMI was calculated as body weight/height ${ }^{2}$. Body composition was assessed by performing MF-BIA in standardized conditions (ie, ambient temperature between $23^{\circ} \mathrm{C}$ and $25^{\circ} \mathrm{C}$, fast of $>3$ hours, empty bladder, clean skin surface), using a Human Im-Touch analyzer (C DS Medica S.r.1., 
Milan, Italy). In addition, participants were asked to remain in the supine position for at least 10 minutes before starting the measurement, with legs and arms slightly abducted at $30^{\circ}$ so there was no contact between the extremities and trunk.

A standard tetrapolar technique was used, with the measuring electrodes placed on the anterior surface of the wrist and ankle, and the injecting electrodes placed on the dorsal surface of the hand and the foot, respectively. $\mathrm{Z}$ was determined at five frequencies $(5,10,50,100$ and $250 \mathrm{kHz})$ with an imperceptible electrical current of $800 \mathrm{~mA}$. In addition, bioelectrical impedance index (BI index) and low- to highfrequency impedance ratio were obtained as follows. BI index was calculated as squared height divided by impedance at $50 \mathrm{kHz}$, representing an established parameter of TBW. ${ }^{31}$ As suggested by previous papers, ${ }^{20,25}$ the ratio between $\mathrm{Z}$ at $5 \mathrm{kHz}$ to $\mathrm{Z}$ at $250 \mathrm{kHz}$ (5/250 impedance ratio) was used as an indicator of fluid distribution between intra-/extracellular compartments and muscle quality. ${ }^{25} \mathrm{In}$ fact, $\mathrm{Z}$ at $5 \mathrm{kHz}$ and $\mathrm{Z}$ at $250 \mathrm{kHz}$ are thought to be inversely related to ECW and TBW, respectively. By considering TBW as the sum of ECW + intracellular water (ICW), for the same ECW, an increase in TBW may be interpreted as an increase in ICW. Finally, FFM and FFM index (fat-free mass index [FFMI] $\mathrm{kg} / \mathrm{m}^{2}=$ FFM/height ${ }^{2}$ ) were estimated from $\mathrm{Z}$ at $50 \mathrm{kHz}$, first using the same BIA equation for both patients and control groups, and then a disease-specific equation for COPD patients only. ${ }^{33}$ Fat mass (FM) was calculated as total body weight minus fat mass index (FFM) and FMI $\left(\mathrm{kg} / \mathrm{m}^{2}\right)$ as $\mathrm{FM} /$ height $^{2}$.

\section{Lung function}

All COPD patients performed a baseline post-bronchodilator spirometry and body plethysmography $\left(\mathrm{QBOX}^{\circledR}\right.$ COSMED, Rome, Italy) according to American Thoracic Society/European Respiratory Society standardization. ${ }^{34} \mathrm{FEV}_{1}$ and FVC were assessed in accordance with the latest Global Initiative for Chronic Obstructive Lung Disease (GOLD) guidelines. ${ }^{35}$ Vital capacity (VC) and inspiratory capacity (IC) were assessed too. Plethysmographic lung volumes, such as total lung capacity (TLC), intrathoracic gas volume (ITGV) and residual volume (RV), were assessed. IC/TLC ratio ${ }^{36}$ was calculated by dividing the difference between TLC and ITGV (TLC minus ITGV) for TLC and was used as a marker for hyperinflation, the abnormal increase in the volume of air remaining in the lungs at the end of spontaneous expiration. ${ }^{37}$

\section{Respiratory muscle strength}

Maximum inspiratory pressures (MIPs) and maximum expiratory pressures (MEPs) were measured according to the method described by Black and Hyatt. ${ }^{38}$ Measurements were obtained in the sitting position with MicroRPM $^{\circledR}$ (CareFusion, Hoechberg, Germany).

\section{Physical fitness}

As measures of physical fitness, handgrip strength (HGS) and 6-minute walk test (6MWT) were performed.

HGS, a surrogate measurement of overall muscle strength, ${ }^{39}$ was measured at baseline with a digital dynamometer (Dynex; MD Systems Inc., Westerville, OH, USA). Three measurements were taken for the dominant side, the maximum values being considered for statistical analysis. ${ }^{40}$

6MWT was performed according to American Thoracic Society standards, ${ }^{41}$ during which oximetry was performed at 10 -second intervals with a pulse oximeter (Nellcor ${ }^{\mathrm{TM}}$ OxiMax N-65; Covidien, Boulder, CO, USA). The 6-minute walk distance (6MWD) was the primary outcome of the $6 \mathrm{MWT}$.

\section{Other measurements}

Breathlessness was measured by using the Medical Research Council dyspnea scale. ${ }^{42}$ A composite prognostic index, the BODE index, ${ }^{43}$ was used as surrogate of global disease severity.

\section{Statistical analyses}

Statistical analysis was performed using SPSS version 20.0 and a $P<0.05$ was considered significant in all analyses. Values were reported as mean \pm standard deviation (SD) unless otherwise specified. Comparisons between COPD patients and controls were conducted by analysis of variance (ANOVA). While Pearson's correlation coefficient was used to evaluate the association between variables, a general linear model (GLM) was applied for adjusting data for age, weight and BMI. Additional analyses were performed in the COPD patients In particular, to evaluate the association of $5 / 250$ impedance ratio with physical fitness and respiratory parameters, male and female patients were also stratified according to the median value of 5/250 impedance ratio.

\section{Results \\ Participants}

After excluding 48 COPD patients who did not satisfy the inclusion and exclusion criteria, 212 patients with stable COPD (144 males and 68 females) and 115 age- and BMImatched controls (53 males and 62 females) were enrolled in this study. Age and BMI were comparable between COPD patients and controls, while a small difference in terms of weight still existed (Table 1). 
Table I General characteristics of 212 COPD patients and II5 controls studied

\begin{tabular}{|c|c|c|c|c|c|c|}
\hline \multirow[t]{2}{*}{ Characteristics } & \multicolumn{3}{|l|}{ Males $(\mathrm{N}=197)$} & \multicolumn{3}{|c|}{ Females $(\mathrm{N}=130)$} \\
\hline & COPD $(N=\mid 44)$ & Controls $(\mathrm{N}=53)$ & $P$-value & COPD $(\mathrm{N}=68)$ & Controls $(\mathbf{N}=62)$ & $P$-value \\
\hline Age (years) & $70.3 \pm 7.3$ & $68.5 \pm 7.8$ & ns & $69.1 \pm 8.2$ & $68.7 \pm 7.0$ & ns \\
\hline Height (cm) & $165.4 \pm 7.0$ & $167.5 \pm 6.9$ & ns & $152.3 \pm 6.4$ & $156.9 \pm 7.5$ & $<0.001$ \\
\hline Weight (kg) & $71.4 \pm 12.6$ & $75.3 \pm 9.3$ & $<0.05$ & $62.7 \pm 10.7$ & $68.0 \pm 8.4$ & $<0.005$ \\
\hline BMI $\left(\mathrm{kg} / \mathrm{m}^{2}\right)$ & $26.0 \pm 3.9$ & $26.7 \pm 2.4$ & ns & $27.0 \pm 4.6$ & $27.6 \pm 2.7$ & ns \\
\hline FFM (kg) & $53.0 \pm 7.2$ & $57.6 \pm 7.4$ & $<0.001$ & $40.3 \pm 3.6$ & $45.3 \pm 5.5$ & $<0.001$ \\
\hline FFMI $\left(\mathrm{kg} / \mathrm{m}^{2}\right)$ & $19.3 \pm 1.4$ & $20.5 \pm 1.7$ & $<0.001$ & $17.4 \pm 1.3$ & $18.3 \pm 1.3$ & $<0.001$ \\
\hline $\mathrm{FM}(\mathrm{kg})$ & $18.4 \pm 7.2$ & $17.7 \pm 5.3$ & ns & $22.4 \pm 7.8$ & $22.8 \pm 5.4$ & ns \\
\hline $\mathrm{FMI}\left(\mathrm{kg} / \mathrm{m}^{2}\right)$ & $6.7 \pm 2.5$ & $6.3 \pm 1.9$ & ns & $9.7 \pm 3.3$ & $9.3 \pm 2.1$ & ns \\
\hline $5 / 250$ impedance ratio & $124.1 \pm 4.9$ & $126.8 \pm 4.7$ & $<0.001$ & $122.3 \pm 4.1$ & $126.0 \pm 3.5$ & $<0.001$ \\
\hline
\end{tabular}

Note: Data are presented as mean \pm standard deviation.

Abbreviations: BMI, body mass index; FFM, fat-free mass; FFMI, fat-free mass index; FM, fat mass; FMI, fat mass index; $5 / 250$ impedance ratio, ratio between $\mathrm{Z}$ at $5 \mathrm{kHz}$ and $Z$ at $250 \mathrm{kHz}$; ns, not significant.

Participants had a mean age of $69.9 \pm 7.6$ and $68.6 \pm 7.4$ years and a mean BMI of $26.4 \pm 4.1$ and $27.2 \pm 2.5 \mathrm{~kg} / \mathrm{m}^{2}$ (COPD and controls, respectively). Within the COPD group, patients had a mean $\mathrm{FEV}_{1} \%$ predicted of $45.3 \%$ and $\mathrm{COPD}$ severity ranged from mild to very severe (GOLD I/II/III/IV: $2.5 \% / 30.8 \% / 37.3 \% / 29.4 \%$ ).

\section{Body composition in COPD patients compared to controls}

In the unadjusted model, both male and female COPD patients had reduced FFM and FFMI compared to controls, while no difference was seen in FM or FMI. After adjusting for age, weight and BMI, FFM remained significantly reduced (and FM became significantly higher) in COPD patients compared to controls (between-group difference $2.33 \mathrm{~kg} ; P<0.001)$.

With respect to raw MF-BIA data, the 5/250 impedance ratio was found to be significantly lower in COPD patients compared to controls in both males (124.1 \pm 4.9 vs $126.8 \pm 4.7$;
$P<0.001)$ and females $(122.3 \pm 4.1$ vs $126.0 \pm 3.5 ; P<0.001)$, even after adjusting for age, weight and BMI $(P<0.001)$.

\section{Impedance ratio in COPD patients}

Determinants of 5/250 impedance ratio in COPD

The 5/250 impedance ratio was higher in male patients compared to female patients $(P<0.001)$. The ratio was inversely related to age in both males $(r=-0.316 ; P<0.001)$ and females $(r=-0.346 ; P<0.005)$. A significant correlation with weight $(r=0.261 ; P<0.001)$, BMI $(r=0.264 ; P<0.001)$, $\operatorname{FFM}(r=0.287 ; P<0.001)$ and FFMI $(r=0.286 ; P<0.001)$ was observed only in males.

Body composition and clinical characteristics in patients with a low 5/250 impedance ratio

In Table 2, COPD patients are stratified according to the median value of the $5 / 250$ impedance ratio. In males, but not in females, lower values of $5 / 250$ impedance ratio were associated with lower BMI $(P<0.01)$, FFMI $(P<0.02)$ and

Table 2 General characteristics and body composition of COPD patients stratified according to the median value of the 5/250 impedance ratio

\begin{tabular}{|c|c|c|c|c|c|c|}
\hline \multirow[t]{3}{*}{ Characteristics } & \multicolumn{6}{|c|}{ Z 5/250 impedance ratio } \\
\hline & \multicolumn{3}{|l|}{ Males } & \multicolumn{3}{|l|}{ Females } \\
\hline & $\begin{array}{l}\text { Below median } \\
\text { value }(n=72)\end{array}$ & $\begin{array}{l}\text { Above median } \\
\text { value }(n=72)\end{array}$ & $P$-value* & $\begin{array}{l}\text { Below median } \\
\text { value }(n=34)\end{array}$ & $\begin{array}{l}\text { Above median } \\
\text { value }(n=34)\end{array}$ & $P$-value* \\
\hline Age (years) & $71.7 \pm 7.6$ & $69.0 \pm 6.8$ & $<0.05$ & $71.3 \pm 8.2$ & $67.1 \pm 7.6$ & $<0.05$ \\
\hline Weight (kg) & $68.7 \pm 14.6$ & $74.0 \pm 13.3$ & $<0.05$ & $61.7 \pm 17.4$ & $64.5 \pm 10.1$ & ns \\
\hline BMI $\left(\mathrm{kg} / \mathrm{m}^{2}\right)$ & $25.2 \pm 3.8$ & $26.9 \pm 3.9$ & $<0.005$ & $26.4 \pm 4.0$ & $27.6 \pm 4.7$ & ns \\
\hline FFMI $\left(\mathrm{kg} / \mathrm{m}^{2}\right)$ & $19.0 \pm 2.0$ & $19.7 \pm 1.9$ & $<0.05$ & $17.4 \pm 2.4$ & $17.5 \pm 1.4$ & ns \\
\hline $\mathrm{FMI}\left(\mathrm{kg} / \mathrm{m}^{2}\right)$ & $6.3 \pm 2.5$ & $7.1 \pm 2.2$ & $<0.05$ & $10.2 \pm 6.9$ & $10.1 \pm 3.4$ & ns \\
\hline HGS (kg) & $25.7 \pm 5.7$ & $33.0 \pm 7.0$ & $<0.001$ & $16.1 \pm 3.3$ & $22.0 \pm 4.9$ & $<0.001$ \\
\hline 6MWD (min) & $0 ; 348$ & $300 ; 434$ & $<0.005$ & $0 ; 60$ & $240 ; 349$ & $<0.05$ \\
\hline
\end{tabular}

Notes: Data are presented as mean \pm standard deviation for all variables, except for 6MWD (as interquartile range). Median value for $5 / 250$ impedance ratio: 124.4 for males; 122.7 for females. $* P<0.05$.

Abbreviations: $5 / 250$ impedance ratio, ratio between $\mathrm{Z}$ at $5 \mathrm{kHz}$ and $\mathrm{Z}$ at $250 \mathrm{kHz}$; BMl, body mass index; FFMI, fat-free mass index; FMI, fat mass index; HGS, handgrip strength - dominant side; 6MWD, 6-minute walk distance; ns, not significant. 
Table 3 Respiratory parameters of 212 COPD patients stratified according to the median value of 5/250 impedance ratio ( 124.4 for males; 122.7 for females)

\begin{tabular}{llll}
\hline Characteristics & \multicolumn{3}{l}{$\mathbf{5 / 2 5 0}$ impedance ratio } \\
\cline { 2 - 4 } & $\begin{array}{l}\text { Below median } \\
\text { value }(\mathbf{n}=\mathbf{1 0 6})\end{array}$ & $\begin{array}{l}\text { Above median } \\
\text { value }(\mathbf{n}=\mathbf{1 0 6})\end{array}$ & P-value* $^{*}$ \\
\hline FEV $_{1}$ (\% predicted) & $42.5 \pm 18.3$ & $47.7 \pm 19.3$ & $<0.05$ \\
VC (\% predicted) & $66.0 \pm 17.8$ & $73.3 \pm 19.0$ & $<0.005$ \\
RV (\% predicted) & $243.1 \pm 66.7$ & $258.9 \pm 68.6$ & $\mathrm{~ns}$ \\
ITGV (\% predicted) & $183.3 \pm 49.1$ & $195.1 \pm 48.9$ & $\mathrm{~ns}$ \\
IC/TLC & $0.3 \pm 0.8$ & $0.2 \pm 0.3$ & $\mathrm{~ns}$ \\
MIP $\left(\mathrm{cm} \cdot \mathrm{H}_{2} \mathrm{O}\right)$ & $49.9 \pm 17.7$ & $61.7 \pm 20.8$ & $<0.001$ \\
MEP $\left(\mathrm{cm} \cdot \mathrm{H}_{2} \mathrm{O}\right)$ & $72.2 \pm 24.2$ & $84.5 \pm 27.3$ & $<0.00 \mathrm{I}$ \\
MRC dyspnea scale & $3.8 \pm 0.4$ & $3.6 \pm 0.5$ & $<0.05$ \\
\hline
\end{tabular}

Notes: Data are presented as mean \pm standard deviation. $* P<0.05$.

Abbreviations: $5 / 250$ impedance ratio, ratio between $Z$ at $5 \mathrm{kHz}$ and $Z$ at $250 \mathrm{kHz}$; FEV , forced expiratory volume in I second; VC, vital capacity; RV, residual volume; ITGV, intrathoracic gas volume; IC, inspiratory capacity; TLC, total lung capacity; MIP, maximum inspiratory pressure; MEP, maximum expiratory pressure; MRC, Medical Research Council; ns, not significant.

FMI $(P<0.05)$. In addition, a significant reduction in HGS (and 6MWD) was seen in both male $(P<0.001)$ and female patients $(P<0.001)$. The same was true for 6MWD (Table 2$)$. All these differences persisted after adjusting for age, weight and BMI. HGS (and 6MWD) was more strongly related to the $5 / 250$ impedance ratio than to FFM or FFMI, in both male ( $r=0.514$ vs $r=0.399$ and vs $r=0.251$, respectively) and female patients ( $r=0.660$ vs $r=0.204$ and vs $r=-0.204$, respectively).

Table 3 shows respiratory parameters of COPD patients stratified according to the median value of the 5/250 impedance ratio. Patients with lower values had significantly lower $\mathrm{FEV}_{1}(P=0.049)$ and $\mathrm{VC}(P=0.005)$, while no difference was found in any of the static lung hyperinflation markers considered (RV, ITGV, IC/TLC).

A

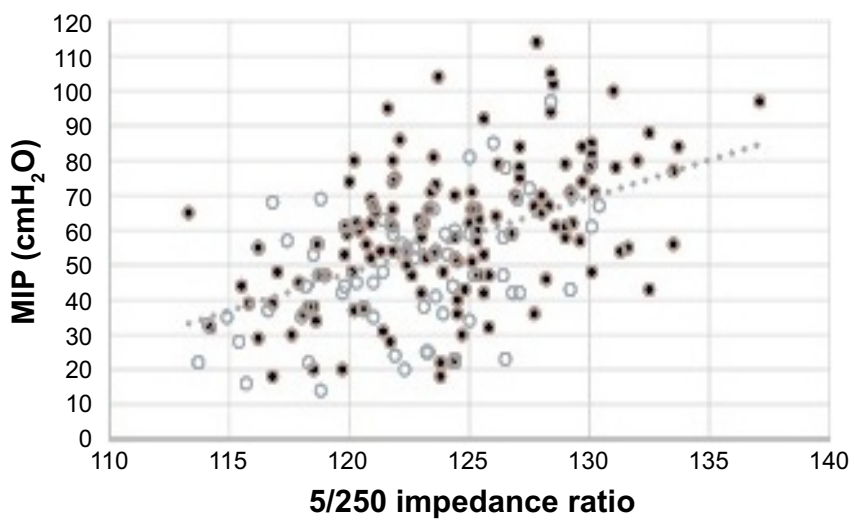

Regarding respiratory muscle strength, both MIP $(P<0.001)$ and MEP $(P=0.001)$ were significantly reduced in patients with lower 5/250 impedance ratio. Actually, MIP and MEP were more strongly related to $5 / 250$ ratio ( $r=0.471$ and $r=0.411$, respectively) (Figure $1 \mathrm{~A}$ and B) than to FFM ( $r=0.352$ and $r=0.346$, respectively) or FFMI ( $r=0.344$ and $r=0.306$, respectively).

Finally, after adjusting for age, weight and BMI, the $5 / 250$ impedance ratio was significantly reduced $(P<0.05)$ in patients with GOLD III and IV, compared to those with GOLD I and II. Likewise, lower 5/250 impedance ratio $(P<0.001)$ was reported in male as well as female patients with a BODE index between 6 and 10 points compared to those with an index between 1 and 5 points, even after adjusting for age, weight and BMI $(P<0.001)$.

\section{Discussion}

The present study indicates that MF-BIA is a valid tool for identifying COPD with poor nutritional status. In particular, the 5/250 impedance ratio was decreased in COPD patients and relates to function and disease severity.

Alteration in nutritional status, which is a systemic effect of COPD, may be assessed using different methods. In particular, BIA is a widely used bedside method to obtain estimates of body composition (TBW and FFM) using predictive equations. ${ }^{44,45}$ In the present study, for consistency, we used the same formula ${ }^{32}$ to estimate FFM and FM in both COPD patients and controls. In accordance with previous papers, ${ }^{12-14}$ our study shows that FFM is significantly lower in COPD patients compared to controls. More interestingly, this difference persisted after adjusting for age, weight and BMI. In other words, COPD patients exhibited a lower ratio between lean tissues and adipose tissue, which is a typical feature of

B

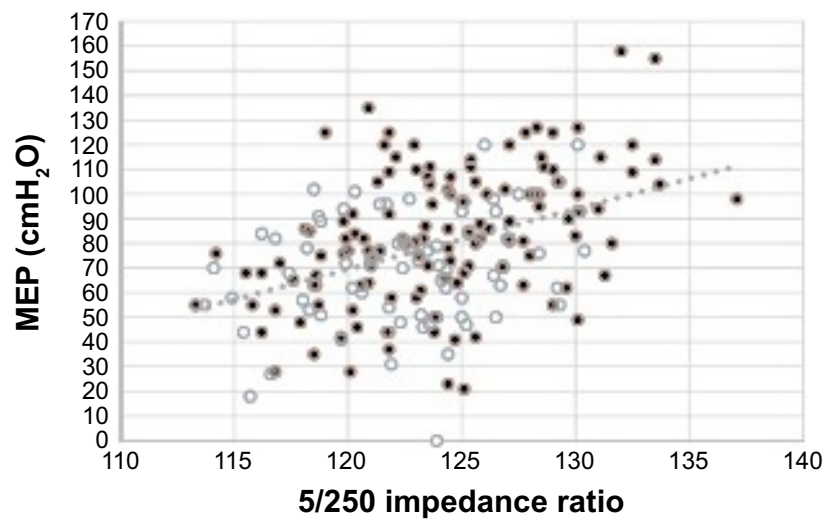

Figure I (A) Relationship between 5/250 impedance ratio and MIP in 212 COPD patients (males in black, females in white) ( $r=0.47$ I, $P<0.00 \mathrm{I})$; (B) relationship between $5 / 250$ impedance ratio and MEP in 212 COPD patients (males in black, females in white) $(r=0.4 I I, P<0.001)$.

Abbreviations: MIP, maximum inspiratory pressure; MEP, maximum expiratory pressure. 
sarcopenia. ${ }^{46}$ Similar findings were obtained when a diseasespecific equation for COPD patients was employed..$^{33}$

Another issue of increasing interest is how to evaluate body composition in the clinical setting using raw BIA variables. In this regard, very few data are so far available for COPD patients; in particular, phase angle, as an index of cell quantity and/or cellular health, was recently shown to be independently associated with measures of physical fitness and disease severity. ${ }^{28,29}$ On the other hand, to the best of our knowledge, there are no data on MF-BIA in COPD patients. MF-BIA measures $Z$ at several frequencies: at low frequency, current is conducted only through ECW, whereas at high frequency, it can penetrate cell membranes, being associated with TBW. ${ }^{26}$ Consequently, low- to high-frequency impedance ratios are raw MF-BIA-derived variables that may provide direct information on both water distribution between intraand extracellular compartments and muscle quality. ${ }^{21,24,27}$

To the best of our knowledge, this is the first study that compared the impedance ratio between COPD and controls. Our results show that the $5 / 250$ impedance ratio is reduced in COPD patients compared to age- and BMI-matched controls (independently of age, weight and BMI) suggesting the presence of a disease-related cellular deterioration.

As far as between-patients variability was considered, age emerged as the most powerful predictor of the 5/250 impedance ratio in both sexes, while after adjusting for age, no relationship persisted with weight, BMI or FFM (data not shown). These results were in line with previous papers showing that phase angle significantly declined with age in COPD patients. ${ }^{29}$

From a clinical point of view, evaluating the relationship between body composition and body functions is a major issue in the diagnosis, assessment and management of chronic diseases. When COPD patients were stratified according to the median value of the $5 / 250$ impedance ratio, those with a lower 5/250 impedance ratio exhibited poorer physical fitness, as estimated by HGS and 6MWD. Even more interestingly, in both sexes, HGS, 6MWD and respiratory muscle strength (MIP and MEP) were more strongly related to the 5/250 impedance ratio than to FFM or FFMI. Furthermore, reduced lung function (ie, $\mathrm{FEV}_{1}$ and $\mathrm{VC}$ ) was also seen in patients with a 5/250 impedance ratio below median value.

Finally, the reduction of the 5/250 impedance ratio was more pronounced in GOLD stages III/IV compared to I/II, even when age and BMI were taken into account as covariates. Likewise, a reduction of the 5/250 impedance ratio was observed in the patients with a higher BODE index (6-10 vs 1-5 BODE score). Thus, differences in the impedance ratio were related to disease severity.

\section{Strength and limitations of the study}

Taking into account that the experimental protocol was carried out in a single center and had cross-sectional study design, to the best of our knowledge, this is the first study that evaluates impedance ratio. In addition, a quite large sample of COPD patients with different disease severity and function impairment was studied. The main limitation is related to the fact that FFM was not concurrently measured with a reference technique, such as DXA. However, DXA does not provide information on water distribution between intra- and extracellular compartments or muscle quality.

Overall, the results of the present study indicate that FFM and the impedance ratio were decreased in COPD patients, even after adjusting for age, weight and BMI. The impedance ratio is affected by clinical conditions, being related to physical fitness and lung function. Thus, MF-BIA may be a useful tool for assessing body composition and nutritional status in COPD patients, especially with respect to cellular integrity and muscle quality.

\section{Conclusion}

Nutritional status is an important determinant of outcome of COPD. The measurement of raw MF-BIA data could be useful as a bedside approach, independently of body composition estimates, by allowing clinicians to identify malnourished patients, even if they are not underweight. Further multicenter studies are needed to better define the role of MF-BIA in assessing changes in nutritional status with time, due to clinical status, rehabilitation and nutritional treatment.

\section{Disclosure}

The authors report no conflicts of interest in this work.

\section{References}

1. Celli BR, Decramer M, Wedzicha JA, et al. An Official American Thoracic Society/European Respiratory Society Statement: research questions in chronic obstructive pulmonary disease. Am J Respir Crit Care Med. 2015;191(7):e4-e27.

2. Divo MJ, Martinez CH, Mannino DM. Ageing and the epidemiology of multimorbidity. Eur Respir J. 2014;44(4):1055-1068.

3. Drazen JM, Fabbri LM. Ageing and multimorbidity. Eur Respir J. 2014; 44(3):557.

4. Faner R, Cruz T, Lopez-Giraldo A, Agusti A. Network medicine, multimorbidity and the lung in the elderly. Eur Respir J. 2014;44(3): 775-788.

5. Gologanu D, Ionita D, Gartonea T, Stanescu C, Bogdan MA. Body composition in patients with chronic obstructive pulmonary disease. Maedica (Buchar). 2014;9(1):25-32.

6. Montes de Oca M, Torres SH, Gonzalez Y, et al. Peripheral muscle composition and health status in patients with COPD. Respir Med. 2006; 100(10):1800-1806.

7. Vermeeren MA, Creutzberg EC, Schols AM, et al. Prevalence of nutritional depletion in a large out-patient population of patients with COPD. Respir Med. 2006;100(8):1349-1355. 
8. Landbo C, Prescott E, Lange P, Vestbo J, Almdal TP. Prognostic value of nutritional status in chronic obstructive pulmonary disease. Am J Respir Crit Care Med. 1999;160(6):1856-1861.

9. Mostert R, Goris A, Weling-Scheepers C, Wouters EF, Schols AM. Tissue depletion and health related quality of life in patients with chronic obstructive pulmonary disease. Respir Med. 2000;94(9):859-867.

10. Creutzberg EC, Schols AM, Bothmer-Quaedvlieg FC, Wouters EF. Prevalence of an elevated resting energy expenditure in patients with chronic obstructive pulmonary disease in relation to body composition and lung function. Eur J Clin Nutr. 1998;52(6):396-401.

11. Hallin R, Janson C, Arnardottir RH, et al. Relation between physical capacity, nutritional status and systemic inflammation in COPD. Clin Respir J. 2011;5(3):136-142.

12. Breyer MK, Rutten EP, Locantore NW, Watkins ML, Miller BE, Wouters EF. Dysregulated adipokine metabolism in chronic obstructive pulmonary disease. Eur J Clin Invest. 2012;42(9):983-991.

13. Hopkinson NS, Li KW, Kehoe A, et al. Vitamin D receptor genotypes influence quadriceps strength in chronic obstructive pulmonary disease. Am J Clin Nutr. 2008;87(2):385-390.

14. Natanek SA, Gosker HR, Slot IG, et al. Heterogeneity of quadriceps muscle phenotype in chronic obstructive pulmonary disease (Copd); implications for stratified medicine? Muscle Nerve. 2013;48(4): 488-497.

15. Daniele A, De Rosa A, Nigro E, et al. Adiponectin oligomerization state and adiponectin receptors airway expression in chronic obstructive pulmonary disease. Int J Biochem Cell Biol. 2012;44(3):563-569.

16. Bianco A, Mazzarella G, Turchiarelli V, et al. Adiponectin: an attractive marker for metabolic disorders in chronic obstructive pulmonary disease (COPD). Nutrients. 2013;5(10):4115-4125.

17. Schols AM, Ferreira IM, Franssen FM, et al. Nutritional assessment and therapy in COPD: a European Respiratory Society statement. Eur Respir J. 2014;44(6):1504-1520.

18. Van Loan MD. Is dual-energy X-ray absorptiometry ready for prime time in the clinical evaluation of body composition? Am J Clin Nutr. 1998;68(6):1155-1156.

19. Kyle UG, Bosaeus I, De Lorenzo AD, et al. Bioelectrical impedance analysis-part II: utilization in clinical practice. Clin Nutr. 2004; 23(6):1430-1453.

20. Mulasi U, Kuchnia AJ, Cole AJ, Earthman CP. Bioimpedance at the bedside: current applications, limitations, and opportunities. Nutr Clin Pract. 2015;30(2):180-193.

21. Castillo Martinez L, Colin Ramirez E, Orea Tejeda A, et al. Bioelectrical impedance and strength measurements in patients with heart failure: comparison with functional class. Nutrition. 2007;23(5):412-418

22. Barbosa-Silva MC, Barros AJ. Bioelectrical impedance analysis in clinical practice: a new perspective on its use beyond body composition equations. Curr Opin Clin Nutr Metab Care. 2005;8(3):311-317.

23. Baumgartner RN, Chumlea WC, Roche AF. Bioelectric impedance phase angle and body composition. Am J Clin Nutr. 1988;48(1):16-23.

24. Norman K, Stobaus N, Pirlich M, Bosy-Westphal A. Bioelectrical phase angle and impedance vector analysis - clinical relevance and applicability of impedance parameters. Clin Nutr. 2012;31(6):854-861.

25. Earthman CP. Body composition tools for assessment of adult malnutrition at the bedside: a tutorial on research considerations and clinical applications. JPEN J Parenter Enteral Nutr. 2015;39(7):787-822.

26. Park J, Yang WS, Kim SB, et al. Usefulness of segmental bioimpedance ratio to determine dry body weight in new hemodialysis patients: a pilot study. Am J Nephrol. 2009;29(1):25-30.

27. Abbas SR, Zhu F, Levin NW. Bioimpedance can solve problems of fluid overload. J Ren Nutr. 2015;25(2):234-237.
28. De Blasio F, Santaniello MG, De Blasio F, Miracco Berlingieri G, Bellofiore B, Scalfi L. BIoelectrical impedance analysis (bia) in the assessment of muscular function in patients suffering from copd. Chest. 2014;145(3_MeetingAbstracts):468A

29. Maddocks M, Kon SS, Jones SE, et al. Bioelectrical impedance phase angle relates to function, disease severity and prognosis in stable chronic obstructive pulmonary disease. Clin Nutr. 2015;34(6):1245-1250.

30. Abbatecola AM, Fumagalli A, Spazzafumo L, et al. Body composition markers in older persons with COPD. Age Ageing. 2014;43(4): 548-553.

31. Heitmann BL. Impedance: a valid method in assessment of body composition? Eur J Clin Nutr. 1994;48(4):228-240.

32. Sun SS, Chumlea WC, Heymsfield SB, et al. Development of bioelectrical impedance analysis prediction equations for body composition with the use of a multicomponent model for use in epidemiologic surveys. Am J Clin Nutr. 2003;77(2):331-340.

33. Rutten EP, Spruit MA, Wouters EF. Critical view on diagnosing muscle wasting by single-frequency bio-electrical impedance in COPD. Respir Med. 2010;104(1):91-98.

34. Miller MR, Hankinson J, Brusasco V, et al. Standardisation of spirometry. Eur Respir J. 2005;26(2):319-338.

35. Vestbo J, Hurd SS, Agusti AG, et al. Global strategy for the diagnosis, management, and prevention of chronic obstructive pulmonary disease: GOLD executive summary. Am J Respir Crit Care Med. 2013; 187(4):347-365.

36. Casanova C, Cote C, de Torres JP, et al. Inspiratory-to-total lung capacity ratio predicts mortality in patients with chronic obstructive pulmonary disease. Am J Respir Crit Care Med. 2005;171(6):591-597.

37. O'Donnell DE. Hyperinflation, dyspnea, and exercise intolerance in chronic obstructive pulmonary disease. Proc Am Thorac Soc. 2006; 3(2):180-184.

38. Black LF, Hyatt RE. Maximal respiratory pressures: normal values and relationship to age and sex. Am Rev Respir Dis. 1969;99(5):696-702.

39. Ling CH, Taekema D, de Craen AJ, Gussekloo J, Westendorp RG, Maier AB. Handgrip strength and mortality in the oldest old population: the Leiden 85-plus study. CMAJ. 2010;182(5):429-435.

40. Vaz M, Thangam S, Prabhu A, Shetty PS. Maximal voluntary contraction as a functional indicator of adult chronic undernutrition. Br J Nutr. 1996;76(1):9-15.

41. ATS Committee on Proficiency Standards for Clinical Pulmonary Function Laboratories. ATS statement: guidelines for the six-minute walk test. Am J Respir Crit Care Med. 2002;166(1):111-117.

42. Fletcher CM, Elmes PC, Fairbairn AS, Wood CH. The significance of respiratory symptoms and the diagnosis of chronic bronchitis in a working population. Br Med J. 1959;2(5147):257-266.

43. Celli BR, Cote CG, Marin JM, et al. The body-mass index, airflow obstruction, dyspnea, and exercise capacity index in chronic obstructive pulmonary disease. $N$ Engl J Med. 2004;350(10):1005-1012.

44. Kyle UG, Bosaeus I, De Lorenzo AD, et al. Bioelectrical impedance analysis - part I: review of principles and methods. Clin Nutr. 2004; 23(5):1226-1243.

45. Earthman C, Traughber D, Dobratz J, Howell W. Bioimpedance spectroscopy for clinical assessment of fluid distribution and body cell mass. Nutr Clin Pract. 2007;22(4):389-405.

46. Muscaritoli M, Anker SD, Argiles J, et al. Consensus definition of sarcopenia, cachexia and pre-cachexia: joint document elaborated by Special Interest Groups (SIG) “cachexia-anorexia in chronic wasting diseases" and "nutrition in geriatrics." Clin Nutr. 2010;29(2):154-159. 


\section{Publish your work in this journal}

The International Journal of COPD is an international, peer-reviewed journal of therapeutics and pharmacology focusing on concise rapid reporting of clinical studies and reviews in COPD. Special focus is given to the pathophysiological processes underlying the disease, intervention programs, patient focused education, and self management protocols.

This journal is indexed on PubMed Central, MedLine and CAS. The manuscript management system is completely online and includes a very quick and fair peer-review system, which is all easy to use. Visit http://www.dovepress.com/testimonials.php to read real quotes from published authors.

Submit your manuscript here: http://www.dovepress.com/international-journal-of-chronic-obstructive-pulmonary-disease-journal 